\title{
A VIRTUDE DA FIDELIDADE: DESEJO, PRAZER E SEXUALIDADE NO PENSAMENTO DE FOUCAULT
}

Paulo Martins da Silva Filho

\begin{abstract}
Tem experiência na área de Filosofia, com ênfase em Filosofia contemporânea e filosofia do Corpo. Graduado pela FAJE - Faculdade Jesuíta de Filosofia e Teologia e pesquisador pelo Cnpq, na área da sexualidade no filósofo Michel Foucault. Graduando em Administração pelo IFMT - Instituto Federal do Mato Grosso. Professor Temporário em Filosofia e Sociologia - UNEMAT - Universidade do Estado do Mato Grosso.E-mail: lordemarthins@gmail.com
\end{abstract}

\section{RESUMO}

$\mathrm{O}$ presente artigo tem como tema central a investigação da sexualidade de forma genealógica no pensamento de Michel Foucault, onde busca-se examinar como funciona os mecanismos de sexo- poder na relação conjugal, buscando a melhor prática para uma ética sexual que correlacione a virtude da temperança para que não haja uma falta e nem um excesso, e qual a sua relevância para a formação do sujeito ético. Além de analisar a relação EU-TU de um sujeito que se constrói com o outro e se completa e realiza-se nessa mesma relação.

PALAVRAS-CHAVE: Michel Foucault. Sexualidade. Ética. Desejo. Poder. Saber.

\section{THE VIRTUE OF FAITHFULNESS: DESIRE, PLEASURE AND SEXUALITY IN THE THOUGHT OF FOUCAULT}

\begin{abstract}
This article has as its central theme the investigation of sexuality in a genealogical way in Michel Foucault's thought, where it seeks to examine how sex-power mechanisms work in the marital relationship, seeking the best practice for a sexual ethic that correlates the virtue of sexuality. temperance so that there is neither a lack nor an excess, and what is its relevance for the formation of the ethical subject. In addition to analyzing the I-TU relationship of a subject that is built with the other and is completed and realized in that same relationship.
\end{abstract}

KEYWORDS: Michel Foucault. Sexuality. Ethic. Wish. Power. Knowledge. 


\section{INTRODUÇÃO}

Todos sabemos que viver é amar. Amar é ter a capacidade de sair de si mesmo, uma busca continua aquilo que nos completa. Amar é ser, uma identidade pessoal do ser humano que é fonte de amor. O homem é um ser que olha para dentro de si e busca o seu auto conhecimento, é único e unificante na qualidade de ser única do seu eu.

O homem é conhecedor de sua incompletude. A própria palavra sexo é particípio passado do verbo latino sec-os: sectum, isto é, seccionado, dividido. É uma parte que procura sua complementaridade.

Para Foucault:

"O termo sexualidade surgiu tardiamente, no início do século XIX Ainda com as palavras do pensador "O uso do termo sexualidade foi estabelecido em torno de um discurso desenvolvido em campos de conhecimentos diversos, p.ex.: científico, religiosos e filosóficos, os quais apresentavam comportamentos que cobriam os mecanismos biológicos de reprodução, como também aplicados num conjunto de regras que se sustentava, que se apoiam em instituições religiosas, jurídicas, médicas e pedagógicas em função das mudanças que fazia o indivíduo a dar valor a sua conduta, seus deveres, prazeres, sentimentos, sensações e sonhos (FOUCAULT, 2009, p.9-10)

A tentativa de Foucault era observar de que forma na sociedade moderna formula-se uma experiência em que os indivíduos são levados a se reconhecer como sujeitos de uma sexualidade, sujeitos que desejam e que não podem ao longo de sua historia não ser visto como homens do desejo ou sujeitos desejantes, fazendo uma análise do que pode ser visto de histórico na sexualidade.

O verdadeiro projeto de Foucault é analisar as práticas pelas quais os indivíduos foram levados a prestar atenção a eles próprios, a se decifrar, se reconhecer, a se confessar como seres de desejos, estabelecendo um caminho que parte do eu para um outro, possibilitando uma relação que aponte a descoberta da verdade do seu eu. Desta maneira, apontar quais são os métodos para cuidar dessa prática pessoal que é a sexualidade de forma que demonstre uma virtude da fidelidade para consigo.

\section{SEXUALIDADE}

O dispositivo da sexualidade não nos remete a pensar somente a genitalidade, mas sim que não existe ser humano sem sexo. Além de fazer parte de sua essência história, a sexualidade é também o que distingue o ser humano da categoria de animalidade, pois 
somente o ser humano é dotado de sexualidade e é, dentre muitas coisas, sexo e genitalidade. A sexualidade é uma dimensão integradora e totalizante do homem que se manifesta em todo o seu ser, marcando e expressando o seu próprio sexo. No ser humano tudo é sexuado, o homem, noutras palavras, é sujeito e objeto de sua sexualidade.

A sexualidade tem acesso a todas as nossas relações: pensamentos, desejos, comportamentos e afetividade que são moldados pelo nosso lado pessoal de viver a sexualidade. Podemos dizer que esta relação se dá em um corpo e que o ser humano não apenas possui esse corpo, mas é um corpo, pois, sua sexualidade é energia fundamental da pessoa humana, substância que é essencial para a existência do ser humano e princípio de seu dinamismo.

Segundo Foucault "O poder está em toda parte; não porque englobe tudo e sim porque provêm de todos os lugares" (FOUCAULT, 1979, p.89). As relações de poder são intencionais, não há poder que se exerça sem uma série de objetivos. Não existe eu sem tu, a pessoa humana forma-se no plural, a saber: no nós. As relações matrimoniais - "focos-locais de poder-saber" (FOUCAULT, 1979, p.94) não são relações diferentes, miram no conjunto da sexualidade o controle, um poder - principalmente no século XVIII em que o casamento se exercia em relações desiguais. A relação corpo-poder se dá no discurso da verdade sobre o sexo no qual Foucault chama de "poder-saber" (FOUCAULT, 1979, p.94).

Trata-se aqui de saber se existe um certo tipo de domínio da sexualidade sobre o signo da carne se é dominada em diferentes formas de discursos, principalmente acerca do casamento como "foco-local" de "poder-saber".

\subsection{O AMOR AO PRÓPRIO SEXO E AO SEXO OPOSTO}

Na obra "O uso dos prazeres", Foucault aborda o tema em relação com os rapazes e afirma que do ponto de vista do pensamento grego é um tema inquietante. Explica que a noção de homossexualidade para os gregos não se dava em escolher entre duas opções "Os gregos não opunham, como duas escolhas excludentes, como dois tipos de comportamento radicalmente diferentes, o amor ao seu próprio sexo ao amor pelo sexo oposto" (FOUCAULT, 2009, p.237).

O interessante neste ponto é a maneira o qual o pensador observa a virtude da temperança em oposição ao homem devasso na sociedade grega, ressaltando que do ponto de vista moral é mais relevante as habilidades de uma pessoa temperante no não descuido da 
entrega de si aos prazeres do que qualquer categoria de prazer que um e outro se deleitava ou até mesmo a sua genitalidade, como diz Foucault "A oposição entre um homem temperante e senhor de si e aquele que se entregava aos prazeres era, do ponto de vista da moral, muito mais importante do que aquilo que distinguia, entre elas, as categorias de prazer às quais era possível consagrar-se mais livremente" (FOUCAULT, 2009, p.237).

O que era objeto de reflexão moral para os gregos no que diz respeito a sexualidade, não eram simplesmente atos sexuais (visto sobre suas diferentes modalidades), nem o desejo e nem mesmo o prazer avaliado sobre os inúmeros objetos e práticas que podem provocá-los, mas a dinâmica que unem estas três esferas de maneira circular do ato que é ligado ao prazer e este que suscita o desejo. Nas palavras de Foucault: “A questão ética colocada não é: quais desejos? quais atos? quais prazeres? Mas: com que força se é levado "pelos prazeres e pelos desejos?" (FOUCAULT, 2009, p.57).

A busca pela temperança se dá justamente no exercício desta dinamicidade (ato, desejo, prazer), permitindo desta forma que se forme uma pessoa temperante e senhor de si mesmo. Mas ter costumes que não eram temperantes não quer dizer que nas relações homossexuais a falta de temperança fosse mais grave que nas relações heterossexuais. No pensamento Foucaultiano "Ter costumes frouxos consistia em não saber resistir nem às mulheres, nem aos rapazes, sem que este último caso fosse mais grave que o outro" (FOUCAULT, 2009, p.237).

Ao se abordar o tema das inclinações gregas tanto para as mulheres quanto para os rapazes tem-se que ressaltar que não se trata de duas escolhas ou até mesmo dois prazeres diferentes ou concorrentes, mas de duas inclinações que são ambas verdadeiras e que podem coexistir perfeitamente em um mesmo individuo, segundo Foucault:

Bissexualidade dos gregos? Se quisermos dizer com isso que um grego podia, simultânea ou alternadamente, amar um rapaz ou uma moça, que um homem casado podia ter seus paidikal, que era recorrente, após as inclinações "para rapazes" na juventude, voltar-se de preferência pelas mulheres, então, pode-se muito bem dizer que eles eram "bissexuais" (FOUCAULT, 2009, p.238).

A reflexão sobre essas duas práticas faz-nos observar que os gregos não reconheciam nesta dupla prática duas espécies de desejo e nem duas pulsões que seriam entre elas

${ }^{1} \pi \alpha 1 \delta$ «ó (Substantivo. acus. pl. neut.): Como substantivo (adjetivo substantivado) neutro plural significa garoto, rapaz amado, favorito. 
entre elas diferentes e concorrentes, compartilhadas no coração do homem e em seus apetites sexuais, mas, sim, uma escolha livre que se dava entre os dois sexos, a saber:

Podemos falar de sua, "bissexualidade" ao pensarmos na livre escolha que eles se davam entre os dois sexos, mas essa possibilidade não era referida por eles a uma estrutura dupla, ambivalentes e "bissexual" do desejo. A seus olhos, o que fazia com que se pudesse desejar um homem ou uma mulher era unicamente o apetite que a natureza tinha implantado no coração do homem para aqueles que são "belos", qualquer que seja o seu sexo (FOUCAULT, 2009, p. 238-239).

O amor ao próprio sexo se trata de um cuidado com o corpo/sexo, refere-se não a experiência de viver o próprio ato tendo como objeto o homem e/ou mulher ao acaso, trata-se de uma experiência integradora do ser humano livre de sua genitalidade. Era uma prática culturalmente valorizada por uma literatura que encantava e uma reflexão que fundamentava suas excelências em relação a busca (do ser humano) por sua completude.

\section{O CASAMENTO}

Para entendermos o tópico acerca do casamento, precisa-se compreender a partir do que as relações sexuais entre marido e mulher constituem uma problematização e, principalmente, sobre o comportamento do marido, a refletir sobre a necessidade da temperança que lhe é necessária em uma época em que era fortemente marcada pela dominação dos homens livres.

O tópico sobre sexualidade e o amor ao próprio sexo e ao sexo oposto é fundamental para que possamos refletir a sociedade grega e a forma de como que eles usavam os prazeres, uma contextualização explicitada, conforme o tópico 1.1, que norteia a base do objeto a ser refletido, a saber: sexualidade e o modo de como os gregos lhe davam com a mesma.

Partindo deste pressuposto acima, adentremos na reflexão acerca do casamento, analisando como a falta de temperança (essa habilidade de dominar os prazeres e desejos) dentro desta relação de poder culminou num problema moral.

Ao tratar essa abordagem sobre o casamento no pensamento de Foucault, há uma necessidade de refletir sobre a seguinte ótica, a saber: como o prazer é visto na relação matrimonial? Foucault parte de dois pontos para refletir a questão, são elas: o estado de poligamia e o estado de monogamia.

Acerca da poligamia, Foucault descreve que "As cortesãs, nós as temos para o prazer; 
as concubinas, para os cuidados de todo o dia; as esposas, para ter uma descendência legítima e uma fiel guardiã do lar” (FOUCAULT, 2009, p. 183).

$\mathrm{Na}$ relação de poligamia o prazer era buscado fora casamento, uma vez que era este tido como apenas uma função procriativa e não de prazer “[...] o objetivo das relações sexuais não devem estar na volúpia, mas na procriação" (FOUCAULT, 2009, p.184).

No que diz respeito a relação monogâmica o homem é proibido pela moral cristã de recorrer a formas de prazer fora daquele que seja com sua esposa, como explana Foucault:

[...] nessa situação estritamente monogâmica, o homem se verá proibido de ir buscar qualquer outra forma de prazer que seja, fora daquele que deve ter com sua esposa legítima; e esse mesmo prazer colocará um número considerável de problemas, já que o objetivo das relações sexuais não deve estar na volúpia, mas na procriação: em torno desta temática central, toda uma interrogação muito estrita se desenvolverá a propósito do estatuto dos prazeres na relação conjugal (FOUCAULT, 2009, p.184).

Sendo assim, Foucault critica que a relação monogâmica cristã não tem em seu horizonte um espirito conciliador que faça com que a questão conjugal relacional esteja concomitante com a questão do prazer, como diz Foucault "Nesse caso, a problematização não nasce da escritura poligâmica, mas da obrigação monogâmica; e ela não procura ligar a qualidade da relação conjugal à intensidade do prazer e à diversidade dos parceiros, mas, ao contrário, dissociar, tanto quanto possível, a constância de uma relação conjugal única da busca do prazer" (FOUCAULT, 2009, p.184).

Desta forma a relação poligâmica não dá início a uma problematização, mas a problematização se dá no paradoxo de uma estrutura monogâmica que divide o prazer do casal, reduz o casamento a uma procriação e desintoniza a relação conjugal do homem com o prazer, que busca em sua cônjuge uma relação integradora de sua sexualidade.

\subsection{DO PRAZER À FIDELIDADE}

No pensamento grego, Foucault destaca a disparidade das regras do casamento, onde classificará o status dos esposos e as obrigações que eram cabíveis a cada um, uma vez que: “A definição daquilo que era permitido, proibido e imposto aos esposos pela instituição do casamento, em matéria de prática sexual, era bastante simples e bastante claramente dissimétrica para que um suplemento de regulação moral não parecesse necessário" 
(FOUCAULT, 2009, p.185).

As esposas eram vistas sob seu status jurídico sexual, onde toda força de sua atividade sexual deveria se manter na relação exclusiva com seu marido. Era imposta a ela o dever de garantir os herdeiros e uma descendência feliz. Em relação ao esposo nenhum tipo de relação sexual lhe era proibida as regra para ele era simples como nos mostra Foucault: "[...] mas ter relações sexuais a não ser com sua esposa legítima ao faz parte, de modo algum, de suas obrigações" (FOUCAULT, 2009, p.186). Era imposto a mulher ter um único marido, ou seja, parceiro exclusivo para que não houvesse confusão na descendência da família, pois seus herdeiros representavam uma estrutura social, econômica e politica de aliança. Em caso de quebra dessa aliança, Foucault aponta as medidas que deveriam ser tomadas, a saber: “"[...] em caso de adultério, as sanções tomadas são de ordem privadas como também pública (uma mulher acusada de adultério não possui mais o direito de aparecer nas cerimônias de culto público" (FOUCAULT, 2009, p.185).

Em relação ao esposo como consequência do vínculo matrimonial apenas não lhe era permitido contrair outro casamento, mas nenhuma relação sexual fora do casamento lhe era proibida. A reflexão até aqui era que o casamento para as mulheres significava uma ligação sexual com seu esposo, o que não era recíproco como demostra Foucault "O casamento de um homem não o liga sexualmente" (FOUCAULT, 2009, p.187). O que definia o adultério até então, não era a quebra do vínculo matrimonial por parte de um dos cônjuges, mas só era estabelecida como violação quando realizado partindo da esposa ao contrair uma relação que não fosse seu esposo “[...] é o status matrimonial da mulher, jamais o do homem, que permite definir uma relação como adultério" (FOUCAULT, 2009, p.187).

Os apontamento de Foucault até aqui é o que nos permite pensar que no casamento grego não existia uma certa fidelidade recíproca ou até mesmo um direito sexual num conjunto moral, jurídico ou religioso pois, o princípio de alteridade é desigual, portanto, não é inclusivo, recíproco de um para com o outro. Para Foucault "O princípio de um duplo monopólio sexual, fazendo os dois esposos parceiros exclusivos, não é requerido na relação matrimonial. Pois se a mulher pertence ao marido, este só pertence a si mesmo" (FOUCAULT, 2009, p.187).

Porém, dentro da estrutura do casamento na Grécia já havia por parte das mulheres um sentimento de ciúmes e reprovação pelo hábito de seus maridos em buscar prazeres em relações extraconjugais. Até mesmo a sociedade esperava de modo geral do homem que 
contraísse casamento uma mudança em sua conduta sexual. Supunha-se que durante a juventude, diante de uma variedade de prazer, que seria bom que após o casamento estive restrito a este. Apesar de que não havia limitação para que o homem buscasse prazer fora de sua relação de marido-cônjuge, não deixava, entretanto, de haver a reflexão do caráter matrimonial, a saber: "Os moralistas - alguns, em todo caso - emitem claramente o principio de que um homem casado não poderia, em boa moral, sentir-se livre para praticar os prazeres como se não fosse casado" (FOUCAULT, 2009, p.188-89).

A reflexão obtida sobre o caráter matrimonial levou os gregos a uma mudança inversa que os aproximou do que hoje podemos denominar de moral cristã:

Tenta-se, frequentemente, reconhecer nestes textos onde a boa conduta do marido é pensada, valorizada e regulada sob a forma da "fidelidade sexual", o esboço de um código moral ainda inexistente: aquele que imporá simetricamente, aos dois esposos, a mesma obrigação de somente praticar as relações sexuais na união conjugal, e o mesmo dever de atribuir-lhes a procriação como fim privilegiado senão exclusivo (FOUCAULT, 2009, p.191)

O que agora proibia o homem casado a buscar o prazer fora do casamento é justamente o exercício do poder em seu oikós por sua conduta dar provas do domínio de si. Desta forma a conduta do marido de poder provar-se como senhor de si está ligada a sua prática em exercer o poder em seu espaço familiar e ter uma relação exclusiva com sua mulher, pois, esta era a mais bela maneira e também exercer seu poder sobre sua mulher.

A harmonia na relação do casamento no que podemos referir a uma fidelidade sexual recíproca, parceiros exclusivos a um dever de sentimento de estar com o outro tenha o espirito de mutualidade, igualmente compartilhado, trata-se de construírem-se como sujeitos mestres de seu modo de ser, agir, pensar, portanto, sua conduta. Uma relação de conhecimento íntimo o qual um regime dos atos sexuais, uma temperança sobre os prazeres é necessária, pois coloca na procriação um poder da própria produção da sexualidade, como aponta Foucault:

Pode-se compreender, assim, por quê a necessidade de um regime para os afrodisia é sublinhada com tanta insistência, enquanto que poucos detalhes são dados sobre os distúrbios que um abuso pode provocar, e poucas precisões sobre o que é preciso fazer ou não fazer. Porque ele é o mais violento dentre todos os prazeres, porque é mais custoso do que a maior parte das atividades físicas, porque ele diz respeito ao jogo da vida e da morte, ele constitui um domínio privilegiado para a formação ética do sujeito (FOUCAULT, 2009, p.175). 
Sujeito este que é marcado por ser capaz de controlar as forcas que dele emana, de ser sábio em poupar sua energia e fazer de sua vida uma arte que vá além de sua existência passageira. O casamento agora é visto sob o principio de alteridade, a possibilidade de um casal dar a vida não apenas a um herdeiro, um sucessor, mas sim a um novo sujeito dotado de sexualidade, fruto de uma fidelidade recíproca e de sentimentos compartilhados, de uma busca e cuidado de si no outro.

\section{A PRUDÊNCIA NO USO DOS PRAZERES}

Ao falarmos em prudência “(...) 'dieta', o regime, é uma categoria fundamental através da qual pode-se pensar a conduta humana; ela caracteriza a maneira pela qual se conduz a própria existência, e permite fixar um conjunto de regras para a conduta: um modo de problematização do comportamento que se faz em função de uma natureza que é preciso conservar e à qual convém conformar-se. O regime é toda uma arte de viver” (FOUCAULT, 2009, p.129). no uso dos prazeres , colacamo-nos a pensar em qual é a relevância na reflexão acerca da problematização do casamento e qual o seu papel na conduta sexual. Foucault busca, em seu pensamento, mostrar o amor na relação de alteridade é superior a uma relação de poder "A questão dos prazeres sexuais e de sua modulação só é considerada a propósito das variações sazonais e após a evocação de alguns princípios gerais de equilíbrio: “É um ponto muito importante para a saúde que a potencia de nosso corpo não seja depreciada por uma outra potencia" (FOUCAULT, 2009, p.144). Essas potencias apontadas por Foucault indica, claramente, a questão de um eu e um tu que não se eliminam em suas relações.

Usando o período grego para expor de que maneira historicamente o sexo, a relação de reciprocidade dos casais e o lugar de busca dos prazeres foi pensado e repensado numa busca pela completude do ser humano. Desta forma, o uso dos prazeres tornou-se o ponto fulminante para se refletir a sexualidade mais que uma simples erótica, mas uma arte de viver bem a dimensão do prazer, pensado e tido sempre na completude das potencias. Segundo Foucault "Em suma, a prática do regime enquanto arte de viver é bem outra coisa que um conjunto de precauções destinadas a evitar as doenças ou terminar de curá-las. É toda uma maneira de se construir como um sujeito que tem por seu corpo o cuidado justo, necessário e suficiente" (FOUCAULT, 2009, p.137).

Faz-se necessária evidenciar que a volúpia fazia parte de uma inquietação dento da 
sociedade grega. Criar uma prudência para o uso dos prazeres, aponta para uma qualidade de vida e saúde melhores com a finalidade de criar um corpo forte, pois é no corpo que se dá a existência do ser humano que precisa ser acompanhado por uma prática reflexiva sobre si mesmo, nas palavras de Foucault: "Cuidado que atravessa a vida cotidiana; que faz as atividades maiores e rotineiras da existência uma questão ao mesmo tempo de saúde e de moral; que define entre o corpo e os elementos que o envolvem uma estratégia circunstancial; e que, enfim, visa armar a próprio individuo com uma conduta racional" (FOUCAULT, 2009, p. 137).

A preocupação em uma prudência no uso dos prazeres era justamente uma forma de refletir sobre a melhoria da saúde do corpo para proporcionar uma ampliação da capacidade do agir e sentir do corpo. Essa ampliação se dá na passagem do reconhecimento do outro não mais como objeto ou responsável pela reprodução de uma descendência feliz e autêntica, mas, sim, como um outro que é capaz de constituir um eu como busca da mais alta verdade do amor que é sentido, expressado e compartilhado de uma sexualidade que é capaz de integração e totalizar o ser humano na busca de conhecer-se a si mesmo à luz do outro.

\subsection{O VERDADEIRO AMOR E A RELAÇÃO COM A VERDADE}

Após toda uma reflexão sobre as relações dos casais e o que significa a busca pelo outro, neste tópico o objetivo é expor a reflexão de Foucault a respeito do verdadeiro amor, ou seja, o sentimento único que condiz os parceiros a partir do amor pela verdade, esta que o outro pode transmitir.

Para refletir acerca do verdadeiro amor Foucault, à luz da erótica socrático-platônica, aponta-nos `pergunta que norteia essa reflexão, a saber: “O que é o amor em seu ser mesmo?" (FOUCAULT, 2009, p.294). Ao buscarmos as respostas para esta pergunta, nós nos deparamos com a temática comum dos amores estagnados que ao passar do tempo, com o avanço da idade do parceiro acaba por resultar por um certo abandono "da relação conjugal" e essa temática proporcionará maior compreensão e embasamento na reflexão acerca do amor.

Foucault fala da necessidade dos casais em fazer dos amantes uma relação de experiência e existência compartilhada, que ao longo do casamento se fortalecerá "[...] não basta associar o amor da alma àquele do corpo; é preciso libertar toda a afeição de suas dimensões físicas (quando se amam 'o corpo e a alma ao mesmo tempo', é o primeiro que predomina, e a perda do frescor da juventude faz passar a própria amizade)" (FOUCAULT, 
2009, p.294). Desta forma podemos distinguir dois elementos que se contrapõem, a saber: o amor que procura no outro apenas a satisfação do próprio prazer e o amor que desperta a necessidade de interesse pelo próprio amado. Foucault sobre esta temática, recorre ao pensamento grego e diz que "No Banquete e nos Memoráveis, Xenofonte apresenta um Sócrates que estabelece uma linha de demarcação rigorosa entre o amor da alma e o amor do corpo, desqualifica nele mesmo o amor do corpo, faz do amor da alma o amor verdadeiro, e busca na amizade, na philia, o princípio que dá valor a toda relação (Sunousia)" (FOUCAULT, 2009, p.294).

O interesse pelo amado envolve algo a mais que um cuidado com o corpo e saúde ou habilidade de manter a temperança. Envolve, dentro da relação existencial dos seres humanos de compartilhar a existência e os sentimentos, a amizade, ou seja, manter uma fidelidade para consigo mesmo de conseguir encontrar no outro a completude que lhe falta. Portanto, uma relação recíproca e fiel do outro da mesma forma encontrar em si esta mesma fidelidade, segundo Foucault “[...] era preciso esperar o momento em que o arrebatamento do amor tivesse cessado e em que a idade, ao excluir os ardores, tivesse afastado os perigos, para que os dois amigos pudessem estar ligados entre si por meio de uma relação de exata reciprocidade". (FOUCAULT, 2009, p. 301).

Esta fidelidade que é uma passagem processual do amor que liga uma ao outro é perpassada pelo momento unificador de conhecer-se e reconhecer-se no outro no sexo "[...] não é a outra metade de si mesmo que o individuo busca no outro; é o verdadeiro com qual sua alma é aparentada" (FOUCAULT, 2009, p. 305).

Na relação sexual, com consentimento não há só encontro de desejos, de prazer, mas corpos que se fundem, satisfazendo seus desejos, e para que as pessoas culminem nesse fim da satisfação de corpos que se encontram e se tornam um, não se dá numa tarefa fácil "Mas o combate que ela teve que sustentar contra a violência de seus apetites ela só pôde travá-lo a partir de uma dupla relação com a verdade: relação com seu próprio desejo, questionado em seu ser, e relação com o objeto de seu desejo reconhecido como ser verdadeiro". (FOUCAULT, 2009, p. 307).

O verdadeiro amor é marcado pelo conhecimento profundo do outro, uma descoberta do seu eu pessoal desvelar-se com o outro no conhecer dos corpos e na partilha da alma “[...] diferentemente do que se passa na arte de cortejar, a 'dialética do amor' exige aqui nos dois amantes dois movimentos exatamente semelhantes; o amor é o mesmo, posto que é, tanto para 
um quanto para o outro, um movimento que os arrebata para o verdadeiro" (FOUCAULT, 2009, p.302).

\section{CONSIDERAÇÕES FINAIS}

Quando falamos de sexo, corpo e poder logo pensamos qual a relação entre estes três conceitos. A reflexão foucaultiana nos mostrará como e por quais motivos esses conceitos são indissociáveis uns dos outros. No que diz respeito ao dispositivo de poder Foucault explicita que não se trata em pensá-lo como algo enraizado numa instituição ou ligado á uma estrutura coercitiva do Estado aos cidadãos, segundo Foucault:

[...] não quero significar "o Poder", como conjunto de instituições e aparelhos garantidores da sujeição dos cidadãos em um Estado determinado. Também não entendo poder como modo de sujeição que, por oposição á violência, tenha a forma da regra. Enfim, não o entendo como um sistema geral de dominação exercida por um elemento ou grupo sobre outro e cujos efeitos, por derivações sucessivas, atravessem o corpo social inteiro (FOUCAULT, 1979, p.88

Foucault considera que o dispositivo de poder é como algo que perpassa o ser humano em todas as suas relações pessoais e interpessoais. As relações, considerando o pensamento do autor, são essas que bem delimitam o jogo majoritário entre o dominante e o dominado, a saber: “... o poder não é uma instituição e nem uma estrutura, não é uma certa potência de que alguns sejam dotados: é o nome dado a uma situação estratégica complexa numa sociedade determinada" (FOUCAULT, 1979, p.89).

Ora, se o poder perpassa o ser humano, temos que destacar que também atravessa o corpo e se realiza na expressão corporal, marcando-se bem presente na relação: Corpo-PoderSexo. Como vimos ao longo deste artigo, o homem é sexo, este que se realiza no corpo em circularidade com os desejos e prazeres que nos remete a refletir também se o verdadeiro objetivo de Foucault era se perguntar sobre o sentido do amor ou sexo.

De fato, Foucault não se propôs a escrever a história da sexualidade buscado o sentido das práticas sexuais, a objetividade do pensamento de Foucault é evidenciar que ao se debruçar sobre um tema que tange toda dimensão humana, que por sua vez nos aponta para uma busca pelo cuidado, uma proposta de preocupação com as práticas que se exerciam sobre o sexo, segundo Foucault: “O projeto era, portanto, o de uma história da sexualidade enquanto experiência, se entendemos por experiência a correlação, em uma cultura, entre campos de saber, tipos de normatividade e formas de subjetividade" (FOUCAULT, 2009, p. 10). 
Entender que os atos sexuais constituem uma dinâmica de prazer entre corpo, sexo e poder são fundamentais para explanar o pensamento de Foucault que se atenta á esta problemática das práticas sexuais as oposições de falta e excesso e a necessidade de ser temperante, explicita-se que: "Na ética dos aphrodisia, a necessidade e a dificuldade do combate se deve, ao contrário, a que ele se desenrola como uma justa consigo mesmo: lutar contra “os desejos e os prazeres” é se medir consigo" (FOUCAULT, 2009, p.84).

Ao nos preocuparmos com desejos e prazeres sexuais, temos que pensá-los como as demais necessidades biológicas. Desta forma, assim como comer e beber em excesso ou em escassez não nos garante uma boa qualidade de vida, temos de ser temperantes para nutrir as práticas, os prazeres e atividades sexuais. Foucault diz que "Em outras palavras, para se constituir como sujeito virtuoso e temperante no uso de seus prazeres, o indivíduo deve instaurar uma relação de si para consigo que é do tipo "dominação-obediência", "comandosubmissão", “domínio-docilidade” (FOUCAULT, 2009, p.87).

É neste ponto que o dispositivo do casamento chama atenção para refletirmos acerca da constituição de um sujeito virtuoso. É neste exercício, através dos escritos e da reflexão de Foucault, que podemos cuidar de nossa sexualidade em seu sentido e prática, numa completude e numa prática de existência onde a liberdade dos corpos estará sempre condicionada, não importa de qual parte, á uma relação de fidelidade de si para consigo e de dominação - obediência, partindo de uma relação em que o outro é reconhecedor de sua incompletude e a experiência da temperança se realiza no fenômeno da unidade do casal que aprende no contraste da relação à prudência de ser temperante.

\section{REFERÊNCIAS BIBLIOGRÁFICAS}

FOUCAULT, Michel. História da sexualidade: o cuidado de si. Rio de Janeiro : Graal, 2009.

FOUCAULT, Michel. História da sexualidade: o uso dos prazeres. 13. ed. . Rio de Janeiro : Graal, 2009.

FOUCAULT, Michel. História da sexualidade: a vontade de saber. Rio de Janeiro: Graal, 1979.

FOUCAULT, Michel. A Hermêutica do sujeito. São Paulo: Martins Fontes, 2004.

FOUCAULT, Michel. Microfisica do poder. $8 a$ ed. Rio de Janeiro: Graael, 1979. 
LEITE, E.S. A Virtude da Fidelidade: Desejo, Prazer e Sexualidade no Pensamento de Foucault. Complexitas - Rev. Fil. Tem. Belém, v. 3, n. 2, p. 15-28, jul./dec. 2018. Disponível em: http://www.periodicos.ufpa.br/index.php/complexitas/article/view/6688>. Acesso em: 05 de agosto de 2019. 